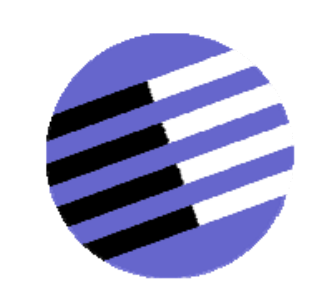

GOVERNANCE AND THE EFFICIENCY

OF ECONOMIC SYSTEMS

GESY

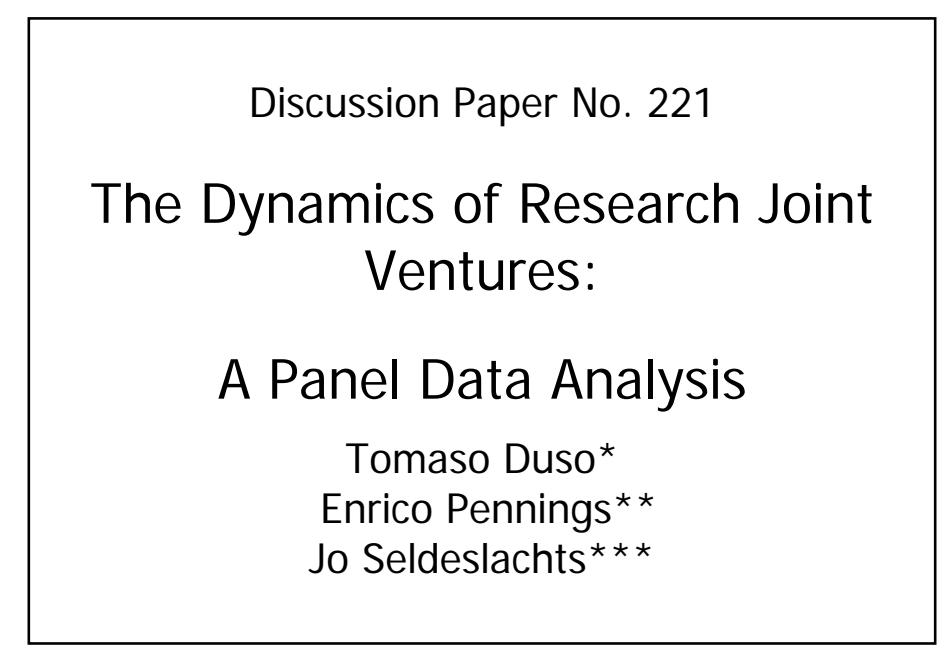

October 26, 2007

*Tomaso Duso, Humboldt University and Wissenschaftszentrum Berlin (WZB) Reichpietschufer 50, 10785 Berlin, Germany; duso@wzb.eu, +49 3025491403

** Enrico Pennings, Dept. of Applied Economics, Erasmus University Rotterdam, P.O. Box 1738, 3000 DR Rotterdam, The Netherlands, pennings@few.eur.nl, +31 104082166

*** J o Seldeslachts, Wissenschaftszentrum Berlin (WZB) Reichpietschufer 50, 10785 Berlin, Germany seldeslachts@wzb.eu, +49 3025491404

Financial support from the Deutsche Forschungsgemeinschaft through SFB/TR 15 is gratefully acknowledged. 


\title{
The Dynamics of Research Joint Ventures: A Panel Data Analysis
}

\author{
Tomaso Duso \\ Humboldt University and Wissenschaftszentrum Berlin (WZB) \\ Reichpietschufer 50, 10785 Berlin, Germany \\ E-Mail : duso@wzb.eu \\ Tel: +49 3025491403 \\ Enrico Pennings \\ Dept. of Applied Economics, Erasmus University Rotterdam \\ P.O. Box 1738, 3000 DR Rotterdam, The Netherlands \\ E-mail: pennings@few.eur.nl \\ Tel: +31 104082166 \\ Jo Seldeslachts * \\ Wissenschaftszentrum Berlin (WZB) \\ Reichpietschufer 50, 10785 Berlin, Germany \\ E-Mail : seldeslachts@wzb.eu \\ Tel: +49 3025491404
}

October 26, 2007

\begin{abstract}
The aim of this paper is to test the determinants of Research Joint Ventures' (RJVs) group dynamics. We look at entry, exit and turbulence in RJVs that have been set up under the US National Cooperative Research Act, which allows for certain antitrust exemptions in order to stimulate firms to cooperate in R\&D. Accounting for unobserved project characteristics and controlling for inter-RJV interactions and industry effects, the Tobit panel regressions show the importance of group and time features for an RJV's evolution. We further identify an average RJV's long-term equilibrium size and assess its determining factors. Ours is a first attempt to produce robust stylized facts about cooperational short- and long-term dynamics, an important but neglected dimension in research cooperations.
\end{abstract}

Keywords: Research Joint Ventures, Dynamics, Panel Data

JEL Classification: C23, L24, O32

* Corresponding author. We wish to thank Jordi Jaumandreu, Tobias Kretschmer and Vicente Salas for helpful discussions; participants of seminars at the WZB, University of Linz, LMU Munich, and at the ASSET Conference (Lisbon), DRUID Conference (Copenhagen), SFB Conference (Mannheim), DEMO Workshop (Barcelona), Summer Workshop on Innovation (Santander) and EARIE Conference (Valencia) for their helpful comments. Kemal Azun, Constanze Quade, Falko Tabbert, Hannes Ullrich, and Kamonthip Wichmann provided excellent research assistance. Tomaso Duso acknowledges financial support from the Deutsche Forschungsgemeinschaft through SFB/TR 15. Jo Seldeslachts recognizes financial assistance from the EC $5^{\text {th }}$ framework program (HPRNCT-2002-00224). 


\section{Introduction}

Though being competitors in the product market, firms often cooperate in research and development (R\&D). The US National Cooperative Research Act of 1984 (NCRA) is exactly created for this purpose. By granting certain antitrust exemptions, the NCRA stimulates firms to cooperate in $\mathrm{R} \& \mathrm{D}$ on a large scale, thereby aiming to provide a solution to perceived competitive threats to US high-tech industries. As a natural consequence of the goal of promoting such broad and loose cooperations, one characteristic of the NCRA collaborations stands out: firms frequently enter and exit the NCRA research joint ventures (NCRA-RJVs) after their initial formation. Indeed, more than $30 \%$ of the NCRA-RJVs experience subsequent firm in-and-out movements, involving more than $75 \%$ of participating firms.

The focus of this paper is to explore these entry and exit processes, as a first step in deepening our understanding of the dynamics of research collaborations. While initial formation choices can be expected to have an important impact, many decisions take place after the alliance is formed. Moreover, as Doz and Hamel (1998, p.15) point out, "Managing the alliance relationship over time is usually more important than crafting the initial formal design”. Our aim, therefore, is to test in a panel data model what factors play an important role in the evolution of NCRA-RJVs. In particular, we single out group and time factors that drive the dynamics of RJVs after their initial setup. Group aspects matter; firms interact and influence each other in an alliance, hence they develop a number of dynamic processes that separate them from a random collection of individual firms. Likewise, an RJV may experience changes over its life-cycle and time is therefore likely to shape its dynamics.

Understanding cooperational dynamics has an interest in its own right, as it provides insights in post-formation changes. As such, our paper should be seen as a contribution aimed at responding to the "[...] need for research on alliance evolution and adaptation," as Reuer et al. 
(2002, p.136) indicate, since “[...] post-formation alliance dynamics and flexibly adapting partnerships are crucial aspects of collaborative strategy”. ${ }^{1}$ Furthermore, given that our main focus lies on group dynamics, we can unravel potential drivers of group processes in the context of research collaborations. The found patterns may indicate relevant dimensions along which one can further develop the theory-building on the endogenous formation of RJVs (see Greenlee, 2005, for an overview). Additionally, gaining insight into RJV dynamics is important from a policy perspective, as it gives indications about the learning processes that take place - or at least about the opportunities of learning - and therefore about the degree of competitiveness of the participating firms, and ultimately the sources of economic progress. ${ }^{2,3}$

We identify factors that drive the RJV movements and do this on the two levels that we think are relevant. First, we analyze how group and time characteristics of a RJV determine its short-run dynamics; i.e. we investigate how the number of insiders and the age of an RJV influence its entry and exit patterns. ${ }^{4}$ We control in this analysis for both unobserved RJV heterogeneity by means of a panel estimation, and observed RJV heterogeneity in terms of (1) potential interaction effects with other RJVs and (2) product market characteristics in which the RJV is embedded.

We find that the size-variables are robust drivers of dynamics in a non-linear way. Especially the found U-shaped impact of the number of insiders on entry into an RJV may be of

\footnotetext{
${ }^{1}$ Our paper could be seen as a natural extension of the current research on NCRA-RJVs, in which scholars have mainly sought to identify factors that determine their formation. Descriptive studies on NCRA-RJVs include Link (1996), Vonortas (1997) and Majewski and Williamson (2002); studies that investigate causal factors of NCRA-RJV participation decisions are Hagedoorn et al. (2000), Röller et al. (2006), and Snyder and Vonortas (2005).

${ }^{2}$ This may be particularly relevant for the RJVs set up under the NCRA, which is designed to promote collaboration in science and technology and to allow firms to benefit to gain competitiveness (Caloghirou et al., 2003).

${ }^{3}$ At the same time, RJV dynamics hint at how RJV participation has an impact on collusion in product markets. For example, frequent entry and exit may indicate that RJV members have less ability and time to establish those mechanisms that improve coordination among members; a better coordination enhances the likelihood of collusion in the product market (Ordover and Baumol, 1988).

${ }^{4}$ With insiders we mean the number of for-profit firms. We will also include as a separate variable the number of non-profit entities participating in the RJV.
} 
interest. This finding potentially indicates that problems of moral hazard at first increase with the number of insiders, i.e. entry initially decreases with size; we thus find indirect evidence for the classic theory of moral hazard in teams (Holmström, 1982), yet in a dynamic rather than a static context. However, those RJVs that are very large, experience more entry when they further increase in size, which hints at some RJVs having overcome the typical problems of large groups - such as free riding and coordination problems - through an optimal design of their organizational variables. Moreover, the age of an RJV has a negative effect on both entry and exit, suggesting that RJVs become more stable over their lifespan.

Second, once the impact of a RJV's size on short-run dynamics is analyzed, one can go a step further and investigate whether a long-term dynamic equilibrium size exists - i.e. if entry and exit evolve around a long-term stable group size. We find that this is indeed the case, which confirms - again in a dynamic rather than static context - RJV-group formation models such as Bloch (1995) that predict an optimal RJV size. Moreover, some of the industry characteristics in which the RJV is embedded are found to have a determinant impact on this group size. In particular, factors which both increase the benefits of learning and the possibility of controlling other RJV members - as for example the concentration of an industry - lead to larger RJVs in the long-run. ${ }^{5}$

Our study should be mainly seen as adding (group) dynamic elements to the existing research on RJVs, which have by and large looked at RJV formation or termination at a particular moment in time. Röller et al. (2007), who also use data from the NCRA, examine incentives for the formation of RJV firm-pairs by estimating an endogenous switching regression

\footnotetext{
${ }^{5}$ A higher industry concentration should make it more beneficial to apply RJV-generated knowledge in the product market; e.g. cost gains have a higher impact on profits when firms enjoy more market power. Also, when an industry is more concentrated, it easier to spot defectors - i.e. firms that apply RJV-knowledge in a way that was not agreed upon - since generally fewer firms operate in the market.
} 
model. Based on the idea that firms enter an RJV to reduce costs and later compete in product markets à la Cournot, they hypothesise and find that firm size asymmetries negatively affect the probability to enter a collaborative agreement. Hernan et al. (2003) use a data set of European RJVs to estimate a firm's participation equation by means of a logit model. In recognising that theoretical models on RJV formation are fairly complex, the authors identify potentially relevant variables and indicate for some of these the expected effect on the probability of RJV participation. On RJV termination, Kogut (1989) investigates the stability of RJVs through the estimation of a hazard model. He finds evidence for his claim that stability is positively enhanced through participants’ ability to reciprocate.

We believe that our approach also offers some methodological advantages when compared with previous studies, which look at whether at a particular moment in time an individual firm is in an RJV or out (Hernan et al., 2003) or pair-wise connected to another RJVparticipant (Röller et al., 2007). ${ }^{6}$. First, we use the time-variation in a panel regression. ${ }^{7}$ Second, given our focus on group dynamics, we take the RJV to be the natural choice as the unit of observation, which generates more variation in our dependent variable, Moreover, as we include all RJVS of the NCRA, our sample does not suffer from selection bias. Finally, our methodology enables us to identify the long-term equilibrium RJV size and its determinants, which should add to the understanding of group formation processes in an R\&D cooperation context.

The structure of the paper is as follows. In the next section we discuss the data. The third section discusses the estimation strategy, the chosen variables, and their expected impact on

\footnotetext{
${ }^{6}$ Röller et al. (2007) use a non-random selection of firms; they lose around $70 \%$ of the observations when matching firm-level data with RJV-participants; Hernan et al. (2003) lose 35\% of their RJV-participants and around 75\% of their control group, due to insufficient firm-level information; they also consider RJV participation only in a particular period in time (1995-1996).

${ }^{7}$ As Bond (2002, p.141) observes: "One cannot estimate real dynamics from observations in a single point of time, and it is rare for cross-sectional data to have sufficient information about previous time periods for dynamic relationships to be observed.”
} 
dynamics. The fourth section presents the econometric results and some robustness checks. Finally, the fifth section concludes.

\section{The Data}

Our data comes from merging two data sources: the NCRA-RJV database with information on RJVs and its participants under the NCRA (1985-1999), ${ }^{8}$ and the Compustat North America database containing firm-specific information on about 22,000 public US firms (1986-1999). Although the NCRA-RJV data are explained in detail in Link (1996) and Vonortas (1997), we give here a short overview of the main issues. The enactment of the National Cooperative Research Act (NCRA) in 1984 and its amended version, the National Cooperative Research and Production Act (NCRPA) were created to stimulate R\&D in the U.S. In particular, this law allows American firms to establish consortia that conduct pre-competitive $R \& D$ and was implemented by the U.S. Congress as part of an industrial policy to improve international competitiveness of American industries and companies. ${ }^{9}$ Under the terms of the NCRA, a notice must be filed with the U.S. Department of Justice disclosing the RJV's principal research content and its initial members; subsequent notifications of changes in membership or research content of RJVs are also required. In return, certain antitrust exemptions are granted to the NCRA-RJVs.

The NCRA-RJV database thus contains information on all RJVs that have registered with the Department of Justice under the auspices of NCRA and its sequel, the NCRPA. Both U.S. and foreign organizations - including firms, universities, and government agencies and laboratories - participate in NCRA-RJVs. Most U.S.-based entities are business firms and about 43 percent of these are publicly traded firms. The remaining firms are mostly 'unclassified' in

\footnotetext{
${ }^{8}$ We thank Nicolas Vonortas from George Washington University for making this data available to us.

${ }^{9}$ Both Japan and the European Union previously used active industrial policies to create comparative advantages for their strategic industries, such as the semiconductor industry and the commercial aircraft industry, and the U.S. felt it was lagging behind.
} 
terms of ownership and are most likely privately held. The very nature of the NCRA implies that the RJVs in this dataset can be seen as research consortia; consortia have typically more than two participants and maintain a low degree of joint commitment by the members. In the remainder of this section, we go into more detail on the specific data used in our analysis. We first explain the characteristics of the dynamic RJVs, then we discuss inter-RJV interactions and finally consider the industry characteristics in which the RJVs are embedded.

\section{Dynamic RJVs}

The aim of the paper is to find the main drivers of in-and-out movements in an RJV, which naturally restricts our interest to those RJVs that experience some activity. Therefore, the sample used for our analysis consists of all RJVs that in at least one year of existence - after their initial setup - experienced entry or exit of firms, i.e. the dynamic RJVs. ${ }^{10}$ Table 1 presents some characteristics of these RJVs, where from here on we omit the adjective 'dynamic' for expositional ease. A first stylized fact of our sample is the steady rise in the number of RJVs from 17 in 1986 to 237 in 1999, proving both the popularity of the NCRA and the dynamism of its RJVs. The average number of for-profit firms or 'insiders' in an RJV over its years of existence is around 50, while the median is about 13 firms/RJV, which clearly indicates that the size distribution of the RJVs is skewed towards the left. Indeed, the number of insiders ranges from 1 to 408 firms. ${ }^{11}$ Figures $1 \mathrm{a}$ and $1 \mathrm{~b}$ show a first aggregate picture of this study’s main variables of interest: a) the average number of firms entering into a RJV per year and b) the average number of firms exiting from a RJV per year, both in relation to the RJV's age. On

\footnotetext{
${ }^{10}$ For analysis on the differences between dynamic and non-dynamic RJVs, see Seldeslachts, Duso and Pennings (2007). Non-dynamic RJVs are shown to be typically very small, consisting of two or three firms that have specific knowledge and work together on a particular project.

${ }^{11}$ Further, on average, there are between 1 and 2 non-profit organizations participating in a RJV (1.65); their number ranges from 0 to 85 .
} 
average, almost four for-profit firms enter an RJV yearly, while we observe about 1.6 exits every year. ${ }^{12}$ Both the average entry and exit -and their variability- roughly decrease with the RJV's age.

\section{Inter RJV-Interactions}

RJVs do not operate in a vacuum, they interact with each other. It is therefore potentially important to control for these interactions. According to the original NCRA files, a SIC2 industry code is assigned to each RJV. We therefore group the RJVs in SIC2 industries and create RJVcluster variables related to RJVs’ median size and size asymmetries per industry. Furthermore, we create a variable that measures the importance of individual firm links with other RJVs (see Table 2 for a more precise definition). The economic reasoning for the use of these variables will be further explained in Section 3 on estimation and choice of variables.

\section{Industry Characteristics}

RJVs’ members operate in industries. Therefore, controlling for industry characteristics might be a useful way to account for observable heterogeneity among RJVs. The Compustat North America database is used to construct industry variables at the SIC2 level. For each industry and for each year, we calculate a measure of concentration (the HHI) as well as medians and standard deviations for several other indicators, such as number of employees, R\&D intensity and Tobin’s Q. Subsequently, each NCRA-RJV is linked to an industry by using the RJV's assigned SIC2 code and the year as matching keys. To account for high-tech industries - and their potential high spillovers - we include dummies for high-tech communications, high-tech manufacturing and

\footnotetext{
${ }^{12}$ The distribution of entering and exiting firms is skewed towards the left; median entry and exit are zero, indicating that many RJVs do not experience any entry or exit in a given year.
} 
high-tech software and computer-related services respectively, as indicated by the AeA. ${ }^{13}$

\section{Estimation and Choice of Variables}

The aim of this study is to investigate the determinants of RJVs' dynamics. Two main features differentiate our study from previous ones. Most notably, we look at 'dynamics' in terms of variation over time by using a panel data approach. Moreover, for several reasons, we choose the RJV as the unit of observation rather than the single firm. This approach, we believe, has several advantages. First, it allows us to better capture dynamics, i.e. how the alliance as a group evolves and transforms over time. If we took the single firm as a unit of observation, we would not have observed a flow of entry and exit processes but rather a maximum of two discrete decisions made by the single firm: entry and exit. When aggregating entry and exit at the RJV level, we have the advantage of enjoying more variation in the group data as compared to individual firm data. Second, given that we observe the aggregate entry into and exit from one RJV, our dependent variables incorporate in a simple way the subtle and complex strategic interactions between individual firms. Third, to use the RJV as the unit of observation allows us to use the entire population of dynamic RJVs set up under the NCRA and to avoid the possible problems of sample selection.

We observe entry and exit of both for-profit and non-profit entities. But, since the objectives and incentives of non-profit organisations are less well defined, we only seek to explain the for-profit firms' dynamics. These dynamics will be expressed in rates. Using absolute numbers of entry and exit could be problematic due to the significant size differences across RJVs. An entry into an RJV with two firms is different to the same entry into an RJV with more

\footnotetext{
${ }^{13}$ The AeA (formerly the American Electronics Association), is a US nationwide non-profit trade association that represents all segments of the technology industry and is dedicated to helping our members' top line and bottom line. SIC codes indicated to be high-tech can be found on http://www.aeanet.org/Publications/IDMK_definition.asp
} 
than 100 members. We therefore chose to use relative measures and use entry and exit rates. The entry rate into RJV $i$ in industry $j$ at time $t$ is defined as the ratio between current entry and past RJV's size (number of insiders): entry $_{i j t}=$ \#firms that enter ${ }_{i j t} /$ insiders $_{i j t-1}$. Similarly, we define exit rate as exit $t_{i j t}=$ \#firms that exit ${ }_{i j t} /$ insiders $_{i j t-1}$. This definition of entry and exit has the additional advantage of solving the integer problem and allows us to use estimation techniques other than count data methods. We further construct a third dependent variable which we call turbulence, representing the sum of entry and exit rates. The main advantage of this variable is that it captures the total dynamics of the RJV.

The dependent variables in our regression are expressed as the logs of the entry rate, exit rate and turbulence. To be more specific, since the rates can take the value of zero, we use the transformation $D Y N_{i j t}=\log \left(x_{i j t}+1\right)$, where $x_{i j t}$ represents our different measures of dynamics (entry rate, exit rates and turbulence, their sum). The estimation method we apply is the random effect panel Tobit regression since our dependent variables are left censored at zero (Wooldridge, 2002): ${ }^{14}$ although our sample consists of the dynamic RJVs, these RJVs still often experience neither entry nor exit in a given year. The empirical specification is therefore the following panel model:

$$
D Y N_{i j t}=\alpha_{0}+\alpha \operatorname{RJV}_{i, t-1}+\beta \operatorname{INTER}_{i j, t-1}+\gamma \operatorname{IND}_{j, t-1}+\eta_{t}+\xi_{i}+\varepsilon_{i, t},
$$

where $R J V_{i}$ is a vector of the RJV's characteristics, containing our main variables of interest. The control variables are grouped into two vectors: the vector $I N T E R_{i j}$ contains the variables related to how RJVs interact with each other, and the vector $I N D_{j}$ contains the industry characteristics. Finally, $\eta_{t}$ are time fixed effects, whereas the error term is partitioned into an RJV specific

\footnotetext{
${ }^{14}$ A standard Tobit fixed effect model would be inconsistent since the fixed effects cannot be treated as incidental parameters in non-linear models without biasing the other model coefficients (as long as $\mathrm{N}>\mathrm{T}$ ).
} 
random component $\xi_{i}$ and an i.i.d. and normally distributed error term $\varepsilon_{i, t}$. The exact content of each vector of variables $\left(R J V_{i}, I N T E R_{i j}\right.$ and $\left.I N D_{j}\right)$ is explained in Table 2 and their descriptive statistics are depicted in Table 3. The variables and their expected impact on RJV dynamics are discussed in the remainder of this section.

\subsection{RJV Characteristics}

We construct a set of variables that measures the main characteristics of the RJV as a group (vector $R J V_{i}$ in equation (1)). Our prime variable of interest is the number of for-profit firms in an RJV or 'insiders'. Pooling R\&D resources in a cooperative RJV may increase a firm's efficiency of production through research synergies, exploitation of scale economies in R\&D, or risk sharing (e.g. Grossman and Shapiro, 1986). The information in an RJV, however, flows also from the firm to the other RJV participants, who are competitors in the product market and therefore do not have completely aligned interests (e.g. Kamien et al., 1992). The formation of a cooperative venture induces therefore two simultaneous effects: on the one hand, the reduction in a firm's own marginal cost increases its profit. On the other hand, the cost reduction of its competitors triggers more aggressive behaviour on their part and leads to a decrease in a participant's profits (absent product market collusion). As the size of the association increases, the cost reduction experienced by a new member increases with respect to the cost reduction of the standing members. Hence, the incentives to admit additional members may decrease with the size of the association (Bloch, 1995). ${ }^{15}$

\footnotetext{
15 Most consortia have an initiation fee as well as a variable annual project contribution. The type of the membership, the size of the participating firm and the extent of involvement with the project are some of the factors that dictate the fees which ranged from \$2,000 to \$25 million per year. While some consortia encourage companies to participate by keeping a very low initiation fee, others tend to be very selective. Participation in the SEMATECHRJV, for example, requires a minimum annual fee of $\$ 1$ million and full participation could cost a firm as much as $\$ 25$ million. Membership in the NCRA-RJVs can thus be restricted.
} 
A second consequence of not having aligned interests is the potential for 'free-riding', where participants try to benefit from other insiders' efforts, but don’t make an effort themselves. This free-riding problem is potentially larger when the RJV is bigger (Holmström, 1982). Furthermore, apart from informational issues, costs of coordination in an RJV are likely to be higher in a larger RJV as coordinating on tasks becomes harder (e.g. Milgrom and Roberts, 1992). Therefore, with only a few members, it may be attractive to admit more members or join as a new member, but these incentives decrease when the RJV becomes larger. In sum, RJV size is expected to have a negative effect on entry. To measure these effects and to account for possible non-linearities, we include the variables INSIDERS and INSIDERS ${ }^{2}$.

The size of the RJV affects firms' exit decisions in similar ways as their entry decisions, but is further substantially complicated by the fact that exit is the outcome of a (research) process (see e.g. Mody, 1993). Further, as is indicated by Reuer et al. (2005), exit may indicate either participation success -the firm has learned what it wanted- or failure -the firm is leaking more info to other insiders than it learns from them. Therefore, since the number of insiders relates to issues of effective learning, info spillovers to partners and free-riding, they are also the likely drivers of exit, but in a more complicated way than for entry. The expected effect of number of insiders on exit is thus not clear ex-ante.

Once the impact of RJV size on short-run entry and exit dynamics is analyzed, one can further investigate whether a long-term equilibrium group size exists. Indeed, Bloch (1995) predicts that RJVs reach an optimal size, as negative effects of RJV-participation outweigh positive effects once a critical number of insiders has been reached. Translated into a dynamic context, one may observe short-term entry and exit, but these dynamics could evolve around the RJV's long-term equilibrium size. In other words, an external shock may lead to a deviation from the equilibrium, but subsequent entry or exit brings the RJV back to its steady state. To determine its existence, one should look at whether the net entry (entry minus exit) in function of the size variables INSIDERS and INSIDERS ${ }^{2}$ is stable around zero. In subsection 4.3 of the 
results, we analyze whether an equilibrium exists and, if yes, which factors determine this equilibrium.

We further include as an additional (size) variable the number of non-profit entities. Non-profit entities (variable INSIDERS NP) present in RJVs do not compete with firms in the product market. It seems therefore clear that their presence has a positive impact on expectations of learning and a negligible impact on the negative free-rider effects (Sinha and Cusumano, 1991). On the other hand, research collaborations with non-profit entities can be harder than expected: researchers in public laboratories do not respond to the same incentives as engineers in private companies. Recent empirical evidence indicates that although collaborations with non-profit entities are expected to be beneficial, they lead to a higher failure rate (Lhuillery and Pfister, 2007). Therefore, we expect both entry and exit to be positively affected by the number of nonprofit entities.

Given that we are also interested in how entry and exit dynamics evolve over time, our other key explanatory variable is the age of an RJV (variable AGE). Nakamura et al. (1996) develop the hypothesis that RJV participation leads to convergent or divergent learning. With convergent learning, insiders’ intangible capabilities become similar and partners do not need each other anymore. Given that (potential) moral hazard problems remain, costs outweigh benefits and firms will exit at this point in time. ${ }^{16}$ On the other hand, in a divergent development, capabilities become dissimilar yet complementary; firms will stay. A RJV is then not an extended ground for competition but a true form of cooperation over time that, when successfully implemented, leads to savings in the development of competitive capabilities (Teece, 1992). Ties formed within the RJV may then constitute a 'lock-in' for participants. Even when such exclusive stipulations are not explicitly specified, there may still be an implicit expectation of loyalty. In sum, RJV dynamics suggest that the objective and the usefulness of staying as an insider can change over time; convergent learning leads to more exit over time, divergent learning to less.

\subsection{Control Variables}

\footnotetext{
16 See also Roy Chowdhury and Roy Chowdhury (2001) for this reasoning. The concept of 'strategic alliances', popularized by management scholars like Hamel et al. (1989), supports this view and suggests that RJVs are extended grounds for competition between insiders. The goal for strategic alliances is to learn a partner' capabilities and to become less dependent on the partner over time.
} 


\section{Interaction Effects}

RJVs do not operate in a vacuum, they interact with each other. It is therefore potentially important to control for these interactions when looking at dynamics. There are two different ways to think about interactions between different RJVs. The first type of interaction is how individual members make links with other RJVs, i.e. whether they participate in several RJVs at the same time. Therefore, we include a variable that measures the average number of links that RJV members have with other RJVs (variable LINKS). A higher 'connectivity' may increase the stability of an RJV because of several reasons; (i) the decrease in informational asymmetries between members through multiple contacts may enhance cooperational efficiencies (Snyder and Vonortas, 2005); (ii) having more links may decrease problems of free-riding through the possibility of punishment in other research cooperations (Kogut, 1989); (iii) more links may also indicate more members with experience in dealing with cooperations (Zollo et al., 2002). All explanations point out to links having a stabilizing impact on exit and turbulence.

A second way of thinking about interactions between RJVs is considering them as interacting groups or coalitions. Following the logic of Bloch (1995) and Cassiman and Greenlee (1999), who find that typically multiple stable RJVs form in the same product market, we group RJVs in industries. ${ }^{17}$ Theoretical papers on the formation and stability of RJVs are sensitive to different assumptions on the membership rules, objective functions, and the process of coalition formation (see Greenlee, 2005, for an overview). These studies do coincide, however, in finding that the resulting stable structure is characterised by having relatively large RJVs (variable GROUP-SIZE) and by large asymmetries in RJVs' sizes (variable GROUP-SIZE_sd). ${ }^{18}$ We test

\footnotetext{
${ }^{17}$ Of course, industry classifications may not perfectly coincide with the real product market. Further, ideally, one should place an RJV not only in the product market, but also in the innovation market. However, this is beyond the scope of this study.

${ }^{18}$ Bloch (1995), Cassiman and Greenlee (1999) and Greenlee (2005) find for quite different modelling assumptions similar outcomes. Firms first form a large RJV, but do not want to include all firms in the industry (see the previous
} 
therefore whether RJV structures with larger but more dispersed RJVs in the same product market are more stable, all else equal.

\section{Industry Variables}

RJVs are embedded in product markets; it therefore makes sense to further control for product market's characteristics on RJVs' dynamics as a way to account for observed heterogeneity among RJVs. We include industry variables as size and dynamics, plus measures that are potentially important in an RJV context - such as R\&D intensity and potential spillovers - as indicated by previous studies on RJVs. We take the industry to be defined at the SIC2 level to be as inclusive as possible with respect to participating firms’ primary level of activity.

Bloch (1995), Poyago-Theotoky (1995) and more recently Greenlee (2005) predict that when industries become larger, the negative effect on downstream product market competition of taking in an additional firm in the RJV becomes smaller. As a consequence, a larger industry in terms of number of firms (variable FIRMS SIC2) induces RJVs to be relatively larger. Assuming that RJVs do not instantly reach their optimal size, one may therefore expect more entry (and fewer exits) in RJVs when an industry includes more firms.

One can make this argument more dynamic. If a particular industry enjoys more entry (suffers more exits), this should then be reflected in additional entry (less entry) in existing RJVs and less exit (more exit) out of existing RJVs. On the other hand, a more turbulent industry may create less certainty on what the expected rewards of research cooperation are, since it is less clear how these translate into higher profits. ${ }^{19}$ In sum, more firms entering in the product markets

section for this argument). The firms that are excluded from this association have an incentive to form competing groups. Members of the first association, preferring dispersed rivals, then choose to admit more members as a way to reduce the size of rival associations. In equilibrium, the association structure is asymmetric, since the first associations formed comprise more members than the last.

${ }^{19}$ It certainly makes product market collusion a less attractive motivation for RJV participation. See Ivaldi et al. 
make RJV participation more attractive, but more turbulence in product markets makes it less interesting. The expected signs for variables ENTRY SIC2 and EXIT SIC2 depend on which effect dominates.

A similar reasoning can be applied to an industry's concentration. The greater an industry's concentration, the greater the scope for effective internalisation of potential research spillovers, the more beneficial it is to apply generated knowledge (Hernan et al, 2003), and the easier to collude in product markets through RJV participation (Ordover and Baumol, 1988). In addition, a greater concentration (variable $H H I$ ) makes it easier for firms to identify appropriate research partners. In sum, a higher concentration is expected to generate more entry (less exit).

A firm’s size is often connected to research cooperation. The argument goes that larger firms have a higher absorptive capacity and suffer relatively less from any fixed costs that cooperation brings. Larger firms therefore benefit more from research spillovers in an alliance (Sinha and Cusumano, 1991). Further, larger firms may also more effectively exert influence over what happens to the research output of the RJV, i.e. they have more power to punish potential free-riders, both in the RJV but especially in the product market. Therefore, when the average size (variable FIRM SIZE, measured in number of employees) in an industry is higher, one may expect more RJV entry. On the other hand, the differences in firms' sizes (variable FIRM SIZE_sd) may lead to the larger firms having less incentive to participate in research collaboration, as Röller et al. (2007) show. ${ }^{20}$

Cost reductions and product innovations resulting from a successful RJV will be more important in $\mathrm{R} \& \mathrm{D}$ intensive industries (variable $R \& D$ INTENSITY), all else equal. Hernan et al.

(2003) for the rationale of how stable product markets and high barriers to entry and exit facilitate collusion.

20 They reason that research collaboration may make participants more symmetric, which damages especially larger firms. This reasoning, however, hinges on the assumptions that firms cooperate in order to avoid duplication of R\&D expenses and they become more symmetric over time. If firms with complementary skills cooperate, however, and firms stay that way over time, then large firms may want to cooperate with small firms, since these will be less likely to become aggressive competitors in the product market (Sinha and Cusumano, 1991). 
(2003) obtain a positive and significant effect of R\&D intensity on the probability of RJV formation. Kogut (1989) further suggests that RJVs in R\&D-intensive sectors are more likely to involve large scale and long-term projects and would therefore show fewer exits. Moreover, we include the variable $R \& D$ INTENSITY_sd as a control for a possible effect of asymmetries in R\&D expenses across firms in the industry. Growth opportunities, as measured by Tobin’s Q (variable TOBIN'S $Q$ ) is included as a further control variable as well as asymmetries in Tobin's Q (variable TOBIN'S Q_sd). Growth opportunities may generate more entry, as there are more learning and application opportunities in growing sectors.

Finally, to account for the fact that high-tech industries may be different from others especially in terms of having higher spillovers we include dummies for three types of high-tech industries as defined by the AeA (formerly the American Electronics Association). One could expect that firms have more incentives to join RJVs when they are in high-tech industries, due to higher gains from cooperation and internalisation of spillovers (Poyago-Theotoky, 1995).

\section{Results}

We first discuss how the RJV characteristics determine short-run dynamics and shortly report the impact of the control variables. We then investigate whether a long-term equilibrium exists and which factors influence this equilibrium.

\subsection{Impact of RJV Characteristics on Short-Run Dynamics}

Table 4 presents the results of the panel Tobit regressions where we use only an RJV's size and age as our main explanatory variables. The results indicate a U-shaped impact of the number of insiders on entry, i.e. the coefficient of INSIDERS is negative and significant while the coefficient for INSIDERS ${ }^{2}$ is positive and significant. The marginal effect of the number of 
insiders on the entry rate is negative up to approximately 121 for-profit firms - remember that our variables are in logs - and turns positive for larger numbers of insiders. The findings partly confirm our hypothesis that larger RJVs attract relatively less entry, though only up to a critical size. For the RJVs that at some point in time constitute more than 121 for-profit members which is around $10 \%$ of our observations - becoming larger seems to induce even more entry. A reason for this finding may be that very large dynamic RJVs have shown that they are successfully managed and have overcome problems of free-riding and coordination, thereby attracting even more members.

For exit, the observed pattern is different; the larger the RJV, the more we observe firms to exit, although at a decreasing rate (in our sample, the inflection point is never reached). We further find, perhaps surprisingly, the number of non-profit participants (variable INSIDERS NP) to have no significant effect on entry, but to significantly induce more exit. Finally, the age of an RJV has a negative and highly significant impact on both entry and exit, indicating that RJVs become more stable over time. Both effects suggest that divergent learning takes place when RJVs mature, leading to more stable RJVs over time. ${ }^{21}$

\subsection{Impact of Control Variables on Short-Run Dynamics}

\section{Interaction Effects}

Table 5 shows that the results for our main variables are robust to adding the interaction control variables; both the level of significance and magnitude of coefficients for insiders and age do not change. Further, we find a negative effect for our LINKS variable on exit, which conforms to our hypothesized effect. It seems that insiders that have more links with other RJVs are more likely

\footnotetext{
${ }^{21}$ An additional explanation for this finding may be that there exists some 'sleeping' RJVs; some older RJVs may experience no research activity, and hence no new firms want to enter. Still, the insiders may not exit when being a member has negligible costs.
} 
to benefit from a cooperation. Moreover, we find some support for the argument that RJVs act as interacting coalitions in the same product market: the GROUP SIZE variable has a significant and negative effect on a RJV's stability, as predicted. However, larger group size asymmetry (variable GROUP SIZE_sd) has a positive effect on the RJV's turbulence, contrary to what was expected from our discussion in the previous section.

\section{Industry Effects}

In Table 6, we report the results when adding the industry characteristics as control variables. First of all, the results for our main variables - age and number of insiders - stay robust to the inclusion of industry controls. In the following, we shortly state how some of the industry variables matter for a RJV’s short-run dynamics.

First, in line with our previous discussion, the number of firms in the industry (variable FIRMS SIC2) positively affects the entry rate and the coefficient is highly significant. Moreover, the dynamics of the product market appear to play some role as well, especially on entry into an RJV. In particular, a less stable product market has a negative effect on the entry rate in an RJV although ENTRY SIC2 is only significant at the 10\% level - which weakly supports the hypothesis that an unstable product market increases uncertainty about gains of RJVparticipation. In line with Hernan et al. (2003), though their setting is static rather than dynamic, we find that both an increase in product market concentration (variable $H H I$ ) and an increase in firm size (variable FIRM SIZE) have a positive and significant effect on entry into an RJV. More asymmetries in firm size (variable FIRM SIZE_sd) have a negative impact on the entry rate, which is similar to the results in Roeller et al (2007). Yet, while Hernan et al. (2003) obtain a positive effect of R\&D intensity on the formation of an RJV, we do not find support for such an effect. Instead, our results suggest asymmetries in R\&D intensity (variable R\&D INTENSITY_sd) 
have a significant and positive effect on entry. Also, the industry average of TOBIN'S $Q$ has a positive effect on entry, suggesting that industries with higher growth opportunities attract more entry into RJVs. Finally, the high-tech dummies for the software and communication industries (dummies HightechS and HightechC) have a positive and significant impact on entry dynamics, which may suggest that higher industry spillovers induce more participation in RJVs where such spillovers can be better internalised. In high-tech manufacturing industries (HightechM), however, we observe a more active exit pattern, which may indicate that the dummies not only capture high industry spillovers.

\subsection{Long-Term Dynamic Equilibrium}

To determine whether a long-term dynamic equilibrium exists on average, one should look at whether the net entry (entry minus exit) in function of the size variables INSIDERS and INSIDERS ${ }^{2}$ is stable around zero. This condition can be written as

$$
\left(\hat{\alpha}_{1}^{\text {Entry }}-\hat{\alpha}_{1}^{\text {Exit }}\right) *(\text { INSIDERS })^{2}+\left(\hat{\alpha}_{2}^{\text {Entry }}-\hat{\alpha}_{2}^{\text {Exit }}\right) *(\operatorname{INSIDERS})+\left(\hat{A}^{\text {Entry }}-\hat{A}^{\text {Exit }}\right) \overline{\mathrm{X}}=0,
$$

where $\bar{X}$ is the vector of the mean value of the control variables and $\hat{A}_{\text {entry }}, \hat{A}_{\text {exit }}$ the vectors of estimated coefficients of the entry and exit equations respectively. Using the coefficients from the entry and exit equations from Table 6 and the mean values from Table 3, one must solve

$$
0.0585 *(\text { INSIDERS })^{2}-0.5986 *(\text { INSIDERS })+1.0450=0 .
$$

It is easy to see that this binomial has a U-shaped form, which produces two solutions for the number of insiders, $I_{1}$ and $I_{2}$, where $I_{1}<I_{2}$ and $I_{1}$ is the only stable solution. ${ }^{22}$ As shown in Table 7, this results in an average stable size of slightly more than nine insiders in an RJV, indicating

\footnotetext{
${ }^{22}$ Given its U-shaped form, a shock that decreases the size of the RJV below $\mathrm{I}_{1}$ will have as a consequence that netentry becomes positive, moving the RJV forward again to the long-term equilibrium $\mathrm{I}_{1}$. On the other hand, a shock that increases the size of the RJV above $\mathrm{I}_{1}$ induces a negative net entry and the number of insiders moves back to $\mathrm{I}_{1}$. For the solution $\mathrm{I}_{2}$, it is easy to see that this is not a stable equilibrium. For example, a shock that increases the size above $\mathrm{I}_{2}$ induces a positive net-entry, thereby drifting further away from $\mathrm{I}_{2}$.
} 
that there exists indeed a long-term dynamic equilibrium. This prediction is relatively close to the median RJV size of our sample -which is equal to 11 - giving some validity to our approach.

Once confirmed that there exists a dynamic long-term equilibrium, one can identify which factors play a determinant role on this equilibrium size. Since we have estimated both equations separately, however, it is not known what the resulting variance-covariance matrix from the entry and exit equations is. Yet, one can impose an intermediate correlation of zero; under this assumption, we find four factors to have a significant positive impact and one factor to have a significant negative impact on the long-term equilibrium size. An industry’s concentration (variable $H H I$ ), belonging to a high-tech communications industry (dummy HightechC), and the number and average size of firms in an industry (variables FIRMS SIC2 and FIRM SIZE) have a positive impact on an RJV's equilibrium size. More entry in the industry in which an RJV is embedded (ENTRY SIC2), on the other hand, induces an RJV to be smaller on average. ${ }^{23}$

Therefore, first, one can tentatively conclude that we empirically confirm that a stable equilibrium exists and the number of firms in an industry has a positive impact on this equilibrium size, thereby giving a dynamic 'flavour' to predictions from theoretical RJV formation models (as e.g. Bloch, 1995, and Greenlee, 2005). Second, our results indicate that larger firms that compete in more concentrated and stable product markets seek to cooperate in larger RJVs. All three factors - larger firm size, higher industry concentration and less entry into the industry - may contribute to larger RJVs in two ways. First, they induce a more beneficial learning in RJVs. Larger firms have a higher absorptive capacity and it is easier to apply the obtained RJV-knowledge in a more concentrated and stable industry. Second, all three factors may allow for a better control of potential free-riders. Indeed, larger firms operating in more

\footnotetext{
${ }^{23}$ One can also apply the most stringent condition and assume a negative correlation of minus one. We then find that only the variable $H H I$ and the dummy HightechC have a significant impact.
} 
concentrated and stable industries have more possibilities to detect - and punish - any potential free-riding of other insiders.

Finally, in Table 7 we report the predicted long-term equilibrium sizes for the most represented industries and compare these with the actual median sizes. Taking into account that we estimated average coefficients over all industries, our predictions seemly provide a reasonable assessment, both in terms of predicting the actual values and in terms of predicting the relative sizes across industries. E.g. both predicted and median values point towards SIC48 'Communications' as harbouring the largest RJVs and SIC13 'Oil and Gas Extraction' the smallest. Therefore, one may interpret our results as having some predictive power in terms of distinguishing relative RJV sizes across industries, and why these differences exist (i.e. the determining factors of an RJV equilibrium size).

\subsection{Robustness Checks}

In order to check the robustness of our findings, we performed a number of alternative specifications and tests that we thought as relevant.

\section{Size Subsamples}

We divided the sample in three sub-groups according to size and ran all our specifications on each. ${ }^{24}$ For the entry equation, first remember the observed pattern in the full sample: Entry is lower for a higher number of insiders until a critical level of 121 insiders; then entry increases with size. Given that this critical size level is reached in the subsample of large-sized RJVs, we should observe this U-shaped effect only for the largest RJVs and a negative effect of size on

\footnotetext{
${ }^{24}$ We define 'small RJVs' as the first quartile of the RJVs' size distribution (number of for-profit firms $\leq 7$ ), 'medium-sized RJVs' as the second and third quartiles ( $7<$ number of for-profit firms $\leq 22)$, and 'large RJVs' as the top quartile (number of for-profit firms $>22$ ).
} 
entry in the subsamples of small and medium-sized RJVs. This expectation is indeed confirmed; we find a U-shaped pattern for large RJVs and a negative relation between size and entry though not significant - for small and medium-sized RJVs. For the exit equation, we estimate a positive effect of size for small and medium RJVs and an inverse U-shaped effect for large RJVs. Although it must be mentioned that the found effects are not significant, results are consistent with our average findings. Further, for all three subsamples, age has a negative and significant impact on both entry and exit, as was also found in the full sample.

\section{Industry Subsamples}

We ran each of the proposed regressions at the industry level as defined by the SIC2 codes. As expected, we lose some precision in the coefficients' estimates since the subsamples are much smaller. Overall, the found average effects of size and age on entry/exit dynamics are largely confirmed in each separate industry, which indicates that the found patterns, although averages across industries, reflect mostly patterns of the individual industries. We report only the industries where the found patterns differ. The industries SIC13 'Oil and gas extraction' and SIC28 'Chemicals and Allied Products show an inverse U-shaped relationship between size and entry, though the coefficients are not significant. Further, the industries SIC28 and SIC36 'Electric Equipment and Components’ present a U-shaped impact of size on exit.

\section{Conclusions}

This paper aims to test the determinants of the NCRA-RJVs' group dynamics after their initial setup. The study addresses two significant but neglected issues. First, it is an attempt to have a first look at RJV dynamics, by meaningfully including the element of time through the use of a panel data approach. Second, we focus on group dynamics of cooperations, as opposed to an 
individuals firm's behaviour in isolation. As research cooperation is inherently a dynamic and a group-driven process, we believe that our study opens an important dimension in the knowledge on research cooperations.

Our approach allows us to identify factors that drive the RJV movements on two levels. First, we analyse how the main RJV characteristics determine its short-term dynamics, i.e. we investigate the impact of an RJV's number of members and age on entry and exit, controlling for possible interactions with other RJVs as well as industry variables. We find that the sizevariables are robust drivers of dynamics in a non-linear way. First, more insiders in an RJV slows down entry. This may indicate that, overall, larger RJVs suffer relatively more from freeriding and the costs of coordination. This slowdown of entry, however, occurs only up to a critical point. Very large RJVs become more attractive the larger they become. One may tentatively deduct from these findings that these large RJVs have overcome the typical problems of large groups through an optimal design of the organizational variables. The decreasing rate of exit for larger RJVs, on the other hand, is harder to interpret, since exit dynamics may indicate either a success or a failure (Reuer and Zollo, 2005). Finally, results indicate that RJVs become more stable over their life-span, suggesting on average divergent learning in RJVs.

Second, we compute the long-term equilibrium size and identify its determinant factors. The existence of this equilibrium confirms (and adds a dynamic dimension to) such models that find research cooperations to reach an equilibrium number of insiders. Moreover, results point out new dimensions that matter for the optimal size. In particular, factors which (i) increase the benefits of learning, such as larger firm size and higher industry concentration, and (ii) increase the possibility of control on RJV members, such as a more stable product market, lead to larger long-term equilibrium RJVs.

Given the lack of both theoretical and empirical research on RJV dynamics, our study 
should be seen as explorative in nature, with the goal of producing robust stylized facts as a base for more structural future theoretical and empirical research. For example, in order to have a better understanding of why firms exit a RJV, one could use detailed firm-level data in a more structural setup to identify whether this is due to a failure or a success. The main point of this paper is that group dynamics add an extra and important dimension to questions about research cooperation, potential and effective learning, and collusive effects of RJVs. The robust stylized facts that we generated indicate dimensions that matter for such movements, and should be interpreted as a starting point for further research. 


\section{References}

Bloch, F., 1995, Endogenous Structures of Association in Oligopolies. The RAND Journal of Economics, 26(3), pp. 537-556.

Bond, S., 2002, Dynamic Panel Data Models: A Guide to Micro-data Methods and Practice. Portuguese Economic Journal 1, pp. 141-162.

Buretha, A., Wolff, S., and Zanfeic, A., 1997, The Two Faces of Learning by Cooperating: The Evolution and Stability of Inter-Firm Agreements in the European Electronics Industry. Journal of Economic Behavior and Organization, 32 (4), pp. 519-537.

Caloghirou, Y., Ioannides, S., and Vonortas, N., 2003, Research Joint Ventures. Journal of Economic Surveys 17 (4), pp. 541-570.

Cassiman, B., B. Greenlee, B., 1999, Product Market Objectives and the Formation of Research Joint Ventures. Managerial and Decision Economics 20 (3), pp 115-130.

Doz, Y., Hamel, G., 1998, Alliance Advantage: The Art of Creating Advantage through Partnering. Harvard Business School Press, Cambridge.

Greenlee, P., 2005, Endogenous Formation Of Competitive Research Sharing Joint Ventures. The Journal of Industrial Economics, 53 (3), pp. 355-391.

Grossman, G., Shapiro, C., 1986, Research Joint Ventures: An Antitrust Analysis. Journal of Law, Economics and Organization 2 (2), pp. 337.

Gulati, R., Khanna, T., Nohria, N., 1998, The Dynamics of Learning Alliances: Competition, Cooperation and Relative Scope. Strategic Management Journal 19 (3), pp. 193210.

Hagedoorn, J., Link, A., Vonortas, N., 2000, Research Partnerships, Research Policy 29, pp. 567-586.

Hamel, G., Doz, Y., Pralahad, C., 1989, Collaborate with your Competitors and Win. Harvard Business Review, pp. 133-139.

Hernan, R., Marin P.L., Siotis, G., 2003, An Empirical Analysis of the Determinants of Research Joint Venture Formation. Journal of Industrial Economics 51, pp. 75-89.

Holmström, B., 1982, Moral Hazard in Teams. Bell Journal of Economics 13 (2), pp. 324-340.

Ivaldi, M., Jullien,B., Rey, P., Seabright P., Tirole, J., 2003, The Economics of Tacit Collusion. Report for DG Competition, European Commission.

Kamien; M., Muller; E., Zang, I., 1992, Research Joint Ventures and R\&D Cartels. The American Economic Review 82(5), pp. 1293-1306.

Kogut, B., 1989, The Stability of Research Joint Ventures, Reciprocity and Competitive Rivalry, The Journal of Industrial Economics, 38 (2), pp. 183-198.

Lhuillery, Pfister, 2007, Failures of R\&D Co-operations: Empirical evidence from a French Community Innovation, WP CEMI.

Link, A., 1996, Research joint ventures: Patterns from Federal Register Filings. Review of Industrial Organization 11(5), pp. 617-628.

Malerba, F., 2007, Innovation and the Dynamics and Evolution of Industries: Progress and Challenges, International Journal of Industrial Organization 25 (4), pp. 675-699.

Majewski, Williamson, 2002, How Do Consortia Organize Collaborative R\&D?

Evidence from the National Cooperative Research Act, mimeo Antitrust Division. US Department of Justice, Economic Analysis Group.

Milgrom, P., Roberts, J., 1992, Economics, Organization and Management. Prentice Hall Inc., Englewood Cliffs, New Jersey. 
Mody, A., 1993, Learning through Alliances, The Journal of Economic Behavior and Organization 20, pp. 151-170.

Nakamura, M., Shaver, J., Yeung, B., 1996, An Empirical Investigation of Joint Venture Dynamics: Evidence from U.S.-Japan Joint Ventures. International Journal of Industrial Organization 14 (4), pp. 521-541.

Ordover, Baumol, 1988, Antitrust Policy and High-Technology Industries. Oxford Review of Economic Policy 4, pp. 13-34.

Poyago-Theotoky, J., 1995, Equilibrium and Optimal Size of a Research Joint Venture in an Oligopoly with Spillovers, Journal of Industrial Economics 43, pp. 209-226.

Reuer, J., Zollo, M., 2005, Termination Outcomes of Research Alliances. Research Policy 34 (1), pp. 101-115.

Reuer, J., Zollo M., and Singh, H., 2002, Post-Formation Dynamics in Strategic Alliances. Strategic Management Journal 23(2), pp. 135-151.

Röller, L.-H., Tombak, M., Siebert, R., 2007, Why Firms Form (Or Do Not Form) RJVs. Economic Journal 117 (522), pp. 1122-1144.

Roy Chowdhury, I., Roy Chowdhury, P., 2001, A Theory of Joint Venture Life-Cycles. International Journal of Industrial Organization 19 (3-4), pp. 319-343.

Seldeslachts, Duso, Pennings (2007), Research Joint Ventures' Stability and Product Market Collusion, mimeo.

Sinha, D., and Cusumano, M., 1991, Complementary Resources and Cooperative Research: A Model of Research Joint Ventures among Competitors. Management Science, 37 (9), pp. 1091-1106

Snyder, C., Vonortas, N., 2005, Multiproject Contact in Research Joint Ventures: Evidence and Theory. Journal of Economic Behavior and Organization 58, pp. 459-486.

Teece, D., 1992, Competition, Cooperation and Innovation. Journal of Economic Behavior and Organization 18, pp. 1-25.

Vonortas, N.S., 1997, Research Joint Ventures in the U.S., Research Policy 26, pp. 577595.

Wooldridge, J., 2002, Econometric Analysis of Cross Section and Panel Data. MIT Press.

Zollo, M., Reuer, J., Singh, H., 2002, Interorganizational Routines and Performance in Strategic Alliances. Organization Science 13 (6), pp. 701-713. 


\section{Figures and Tables}

Figure 1. Average Entries and Exits in a Dynamic RJV

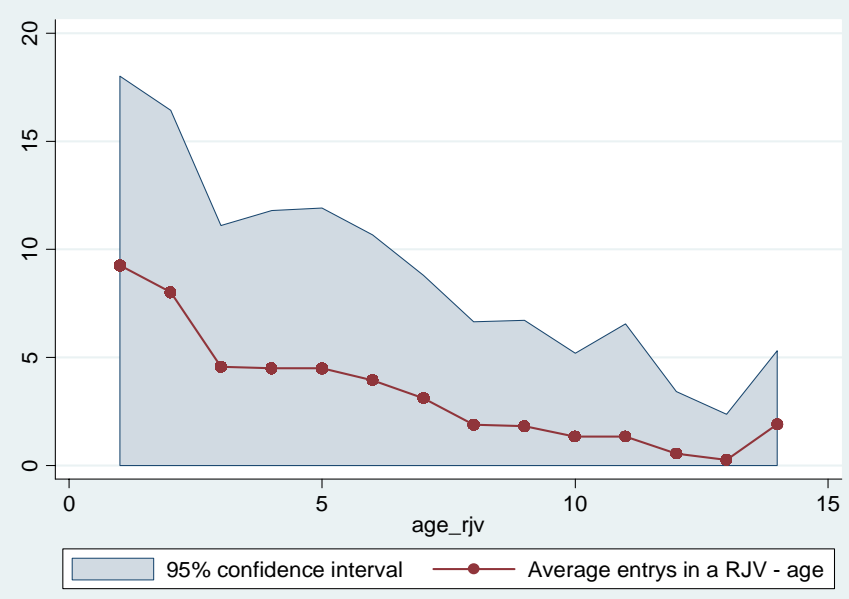

a) Average Entries over the RJV’s age

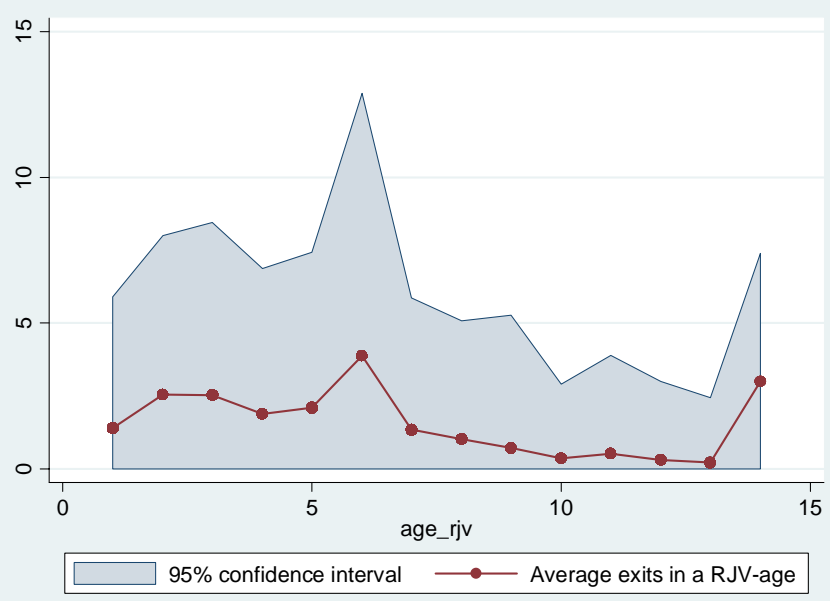

b) Average Exits over the RJV's age 
Table 1. Descriptive Statistics - Characteristics of Dynamic RJVs

\begin{tabular}{lrrrrr}
\hline & Mean & Median & St. Dev. & Min & Max \\
\hline Number of RJVs & 119.47 & 119 & 68.48 & 1 & 237. \\
Number of participants in an RJV & 30.24 & 11 & 53.64 & 2 & 478 \\
Number of for-profit firms & 28.59 & 11 & 49.91 & 1 & 408 \\
Number of non-profit firms & 1.67 & 0 & 8.30 & 0 & 85 \\
Entries of for-profit firms (excluding formation year) & 3.88 & 0 & 11.72 & 0 & 122 \\
Exits of for-profit firms (excluding formation year) & 1.57 & 0 & 7.80 & 0 & 205 \\
Age of the RJV & 5.86 & 6 & 3.97 & 0 & 14 \\
Links & 26.91 & 12.83 & 29.18 & 1 & 136.33 \\
Median RJV size in a SIC2 industry & 18.00 & 14 & 14.63 & 4 & 103 \\
St. Dev. of RJV size in a SIC2 industry & 32.08 & 26.70 & 29.92 & 0 & 95.33 \\
\hline
\end{tabular}


Table 2. Description of the Variables Used in the Regressions

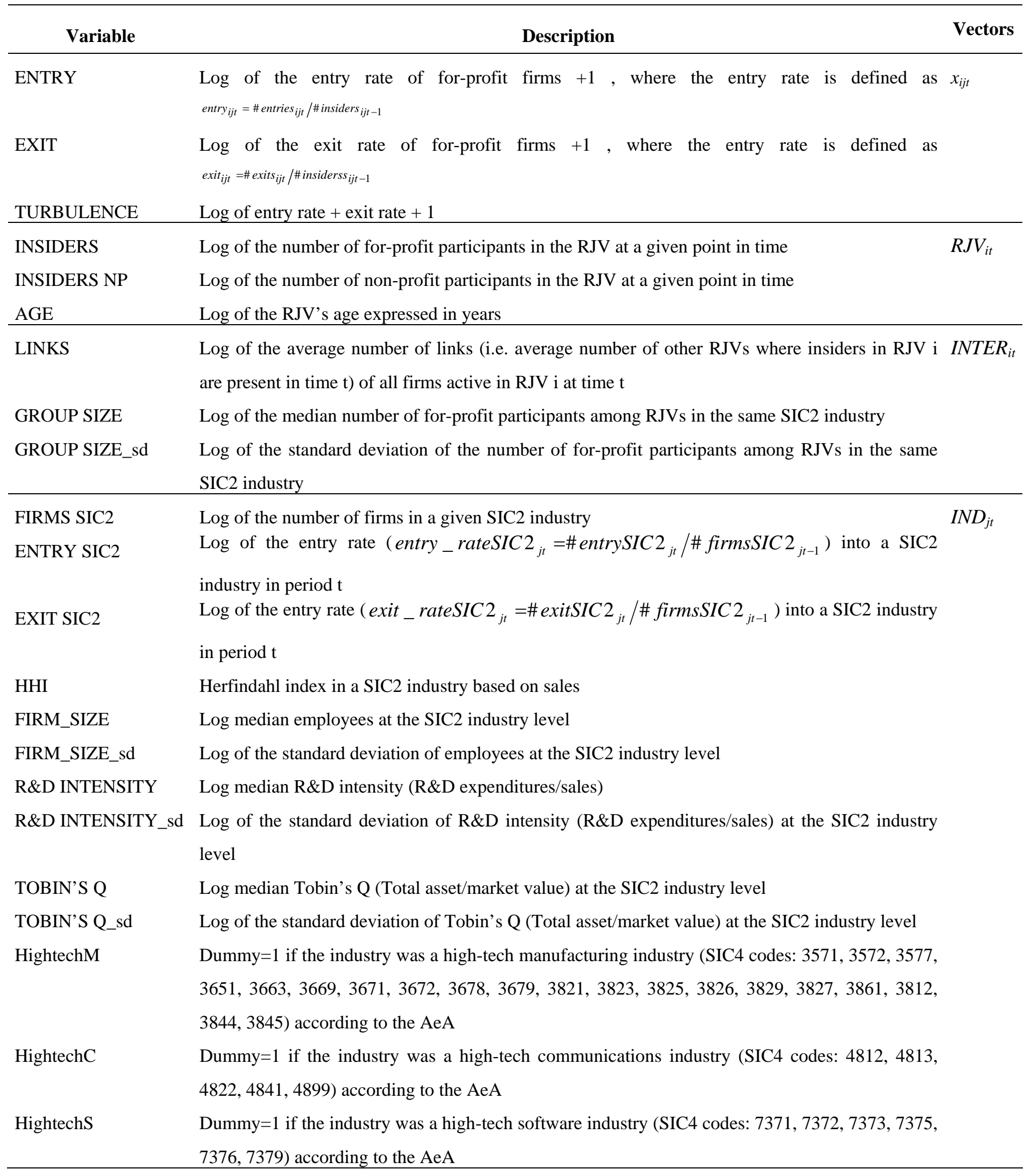


Table 3. Preliminary Statistics - Variables used in the Regressions

\begin{tabular}{|c|c|c|c|c|c|}
\hline Variable & Obs & Mean & Std. Dev. & Min & Max \\
\hline ENTRY & 1657 & 0.11 & 0.25 & 0 & 2.86 \\
\hline EXIT & 1657 & 0.03 & 0.08 & 0 & 0.69 \\
\hline TURBULENCE & 1657 & 0.13 & 0.27 & 0 & 2.86 \\
\hline INSIDERS & 1567 & 2.75 & 0.99 & 0.69 & 5.98 \\
\hline INSIDERS NP & 1549 & 0.28 & 0.76 & 0 & 4.45 \\
\hline AGE & 1558 & 1.62 & 0.76 & 0 & 2.64 \\
\hline LINKS & 1567 & 2.57 & 1.23 & 0 & 4.89 \\
\hline GROUP SIZE & 1567 & 2.08 & 0.61 & 0.69 & 4.42 \\
\hline GROUP SIZE_sd & 1509 & 0.85 & 0.28 & 0 & 1.74 \\
\hline FIRMS SIC2 & 1567 & 5.43 & 1.19 & 0.69 & 7.17 \\
\hline ENTRY SIC2 & 1550 & 0.09 & 0.07 & 0 & 1.38 \\
\hline EXIT SIC2 & 1787 & 0.06 & 0.04 & 0 & 0.51 \\
\hline HHI & 1567 & 0.09 & 0.08 & 0.01 & 0.95 \\
\hline FIRM_SIZE & 1561 & -0.87 & -1.35 & 4.96 & 2.47 \\
\hline FIRM_SIZE_sd & 1564 & 2.55 & -0.97 & 4.55 & 4.69 \\
\hline R\&D INTENSITY & 1542 & 0.07 & 0.08 & 0 & 0.44 \\
\hline R\&D INTENSITY_sd & 1542 & 1.55 & 1.52 & 0 & 5.05 \\
\hline TOBIN'S Q & 1566 & 0.73 & 0.25 & 0.10 & 1.23 \\
\hline TOBIN’S Q_sd & 1561 & 1.75 & 1.10 & 0.17 & 5.14 \\
\hline HightechM & 1804 & 0.06 & 0.23 & 0 & 1 \\
\hline HightechC & 1804 & 0.06 & 0.24 & 0 & 1 \\
\hline HightechS & 1804 & 0.14 & 0.35 & 0 & 1 \\
\hline
\end{tabular}


Table 4. Panel Tobit Regression - RJV's characteristics

\begin{tabular}{|c|c|c|c|c|c|c|c|c|c|}
\hline \multirow[b]{3}{*}{ Constant } & \multicolumn{3}{|c|}{ Turbulence } & \multicolumn{3}{|c|}{ Entry rate } & \multicolumn{3}{|c|}{ Exit rate } \\
\hline & \multirow{2}{*}{$\begin{array}{r}\text { Coef. } \\
0.5316\end{array}$} & \multicolumn{2}{|l|}{ Std. Err } & \multirow{2}{*}{$\begin{array}{r}\text { Coef. } \\
0.9204\end{array}$} & \multicolumn{2}{|l|}{ Std. Err } & \multirow{2}{*}{$\begin{array}{r}\text { Coef. } \\
-0.4755\end{array}$} & \multicolumn{2}{|l|}{ Std. Err } \\
\hline & & 0.1647 & $* * *$ & & 0.1498 & $* * *$ & & 0.0932 & $* * *$ \\
\hline INSIDERS & -0.1821 & 0.1001 & $*$ & -0.3587 & 0.0915 & $* * *$ & 0.1953 & 0.0546 & $* * *$ \\
\hline INSIDERS $^{2}$ & 0.0327 & 0.0145 & $* *$ & 0.0373 & 0.0131 & $* * *$ & -0.0156 & 0.0079 & $* *$ \\
\hline INSIDERS NP & 0.0062 & 0.0259 & & 0.0058 & 0.0233 & & 0.0229 & 0.0114 & $* *$ \\
\hline AGE & -0.3682 & 0.0259 & $* * *$ & -0.3227 & 0.0241 & $* * *$ & -0.0975 & 0.0135 & $* * *$ \\
\hline obs & \multicolumn{3}{|c|}{1540} & \multicolumn{3}{|c|}{1540} & \multicolumn{3}{|c|}{1540} \\
\hline uncensored & \multicolumn{3}{|c|}{468} & \multicolumn{3}{|c|}{440} & \multicolumn{3}{|c|}{273} \\
\hline groups & \multicolumn{3}{|c|}{234} & \multicolumn{3}{|c|}{234} & \multicolumn{3}{|c|}{234} \\
\hline Wald chi2(15) & \multicolumn{3}{|c|}{295.83} & \multicolumn{3}{|c|}{365.69} & \multicolumn{3}{|c|}{128.55} \\
\hline Prob>chi2 & \multicolumn{3}{|c|}{0.0000} & \multicolumn{3}{|c|}{0.0000} & \multicolumn{3}{|c|}{0.0000} \\
\hline Log likelihood & \multicolumn{3}{|c|}{-671.42} & \multicolumn{3}{|c|}{-628.89} & \multicolumn{3}{|c|}{-344.74} \\
\hline
\end{tabular}

All regressions include year dummies. Significance level at the $1 \%, 5 \%, 10 \%$ are represented by ***, **, * respectively. 
Table 5. Panel Tobit Regression - Interaction effects

\begin{tabular}{|c|c|c|c|c|c|c|c|c|c|}
\hline & \multicolumn{3}{|c|}{ Turbulence } & \multicolumn{3}{|c|}{ Entry rate } & \multicolumn{3}{|c|}{ Exit rate } \\
\hline & Coef. & Std. Err & & Coef. & Std. Err & & Coef. & Std. Err & \\
\hline Constant & 0.5076 & 0.2006 & $* *$ & 1.0431 & 0.1838 & $* * *$ & -0.4715 & 0.1076 & $* * *$ \\
\hline INSIDERS & -0.1845 & 0.0990 & $*$ & -0.3798 & 0.0904 & $* * *$ & 0.1852 & 0.0548 & $* * *$ \\
\hline INSIDERS $^{2}$ & 0.0293 & 0.0142 & $* *$ & 0.0357 & 0.0128 & $* * *$ & -0.0168 & 0.0079 & $* *$ \\
\hline INSIDERS NP & 0.0008 & 0.0254 & & 0.0026 & 0.0228 & & 0.0210 & 0.0113 & $*$ \\
\hline AGE & -0.3339 & 0.0269 & $* * *$ & -0.2903 & 0.0248 & $* * *$ & -0.0830 & 0.0139 & $* * *$ \\
\hline LINKS & -0.0269 & 0.0241 & & -0.0338 & 0.0229 & & -0.0191 & 0.0115 & $*$ \\
\hline GROUP SIZE & -0.0622 & 0.0369 & $*$ & -0.0680 & 0.0339 & $* *$ & -0.0488 & 0.0170 & $* * *$ \\
\hline GROUP SIZE_sd & 0.2302 & 0.0890 & $* * *$ & 0.1496 & 0.0829 & $*$ & 0.1703 & 0.0460 & $* * *$ \\
\hline obs & \multicolumn{3}{|c|}{1482} & \multicolumn{3}{|c|}{1482} & \multicolumn{3}{|c|}{1482} \\
\hline uncensored & \multicolumn{3}{|c|}{452} & \multicolumn{3}{|c|}{425} & \multicolumn{3}{|c|}{265} \\
\hline groups & \multicolumn{3}{|c|}{227} & \multicolumn{3}{|c|}{227} & \multicolumn{3}{|c|}{227} \\
\hline Wald chi2(18) & \multicolumn{3}{|c|}{291.71} & \multicolumn{3}{|c|}{364.14} & \multicolumn{3}{|c|}{131.59} \\
\hline Prob>chi2 & \multicolumn{3}{|c|}{0.0000} & \multicolumn{3}{|c|}{0.0000} & \multicolumn{3}{|c|}{0.0000} \\
\hline Log likelihood & \multicolumn{3}{|c|}{-630.47} & \multicolumn{3}{|c|}{-593.77} & \multicolumn{3}{|c|}{-312.65} \\
\hline
\end{tabular}

All regressions include year dummies. Significance level at the $1 \%, 5 \%, 10 \%$ are represented by ***, **, * respectively. 
Table 6. Panel Tobit Regression - Industry Characteristics

\begin{tabular}{|c|c|c|c|c|c|c|c|c|c|}
\hline & \multicolumn{3}{|c|}{ Turbulence } & \multicolumn{3}{|c|}{ Entry rate } & \multicolumn{3}{|c|}{ Exit rate } \\
\hline & Coef. & Std. Err & & Coef. & Std. Err & & Coef. & Std. Err & \\
\hline Constant & -0.6792 & 0.4142 & & 0.0782 & 0.3881 & & -0.8528 & 0.2169 & $* * *$ \\
\hline INSIDERS & -0.1362 & 0.1014 & & -0.3889 & 0.0906 & $* * *$ & 0.2097 & 0.0563 & $* * *$ \\
\hline INSIDERS $^{2}$ & 0.0219 & 0.0149 & & 0.0366 & 0.0130 & $* * *$ & -0.0219 & 0.0082 & $* * *$ \\
\hline INSIDERS NP & 0.0068 & 0.0250 & & 0.0100 & 0.0227 & & 0.0200 & 0.0115 & $*$ \\
\hline AGE & -0.3171 & 0.0282 & $* * *$ & -0.2718 & 0.0263 & $* * *$ & -0.0735 & 0.0152 & $* * *$ \\
\hline LINKS & -0.0444 & 0.0255 & $*$ & -0.0410 & 0.0244 & $*$ & -0.0200 & 0.0130 & \\
\hline GROUP SIZE & -0.0213 & 0.0487 & & -0.0432 & 0.0443 & & -0.0352 & 0.0245 & \\
\hline GROUP SIZE_sd & 0.1028 & 0.1185 & & 0.0233 & 0.1080 & & 0.1708 & 0.0656 & $* * *$ \\
\hline FIRMS SIC2 & 0.1914 & 0.0587 & $* * *$ & 0.1781 & 0.0557 & $* * *$ & 0.0486 & 0.0289 & $*$ \\
\hline ENTRY SIC2 & -0.6257 & 0.4279 & & -0.7333 & 0.3843 & $*$ & 0.1646 & 0.2634 & \\
\hline EXIT SIC2 & -0.9311 & 0.6339 & & -0.8738 & 0.5709 & & -0.1259 & 0.3855 & \\
\hline HHI & 4.2197 & 0.8537 & $* * *$ & 3.3055 & 0.7967 & $* * *$ & 1.0063 & 0.5093 & $* *$ \\
\hline SIZE & 0.1693 & 0.0461 & $* * *$ & 0.1475 & 0.0433 & $* * *$ & 0.0455 & 0.0260 & $*$ \\
\hline SIZE_sd & -0.1500 & 0.0509 & $* * *$ & -0.1425 & 0.0496 & $* * *$ & -0.0592 & 0.0270 & $* *$ \\
\hline R\&D INTENSITY & -0.3788 & 0.4369 & & -0.1980 & 0.3981 & & -0.3801 & 0.2500 & \\
\hline R\&D INTENSITY_sd & 0.0469 & 0.0171 & $* * *$ & 0.0346 & 0.0151 & $* *$ & 0.0124 & 0.0102 & \\
\hline TOBIN’S Q & 0.3878 & 0.1563 & $* *$ & 0.3096 & 0.1432 & $* *$ & 0.2400 & 0.0963 & $* *$ \\
\hline TOBIN’S Q_sd & 0.0021 & 0.0220 & & 0.0007 & 0.0196 & & -0.0176 & 0.0141 & \\
\hline HightechM & 0.1183 & 0.0897 & & 0.1055 & 0.0832 & & 0.1152 & 0.0403 & $* * *$ \\
\hline HightechC & 0.4020 & 0.1022 & $* * *$ & 0.5123 & 0.0951 & $* * *$ & 0.0840 & 0.0504 & $*$ \\
\hline HightechS & 0.0201 & 0.1301 & & 0.2065 & 0.1225 & $*$ & -0.0244 & 0.0685 & \\
\hline obs & \multicolumn{3}{|c|}{1460} & \multicolumn{3}{|c|}{1460} & \multicolumn{3}{|c|}{1460} \\
\hline uncensored & \multicolumn{3}{|c|}{444} & \multicolumn{3}{|c|}{417} & \multicolumn{3}{|c|}{259} \\
\hline groups & \multicolumn{3}{|c|}{227} & \multicolumn{3}{|c|}{227} & \multicolumn{3}{|c|}{227} \\
\hline Wald chi2(30) & \multicolumn{3}{|c|}{342.60} & \multicolumn{3}{|c|}{441.21} & \multicolumn{3}{|c|}{143.58} \\
\hline Prob>chi2 & \multicolumn{3}{|c|}{0.0000} & \multicolumn{3}{|c|}{0.0000} & \multicolumn{3}{|c|}{0.0000} \\
\hline Log likelihood & \multicolumn{3}{|c|}{-597.63} & \multicolumn{3}{|c|}{-562.78} & \multicolumn{3}{|c|}{-296.66} \\
\hline
\end{tabular}

All regressions include year dummies. Significance level at the $1 \%, 5 \%, 10 \%$ are represented by ***, **, * respectively. 


\section{Table 7. Long-Term Equilibrium size}

\begin{tabular}{|c|c|c|c|}
\hline Industry & Description & $\begin{array}{c}\text { Equilibrium } \\
\text { size } \\
\end{array}$ & $\begin{array}{c}\text { Median } \\
\text { Sample size }\end{array}$ \\
\hline SIC 13 & Oil and Gas Extraction & 5.87 & 9 \\
\hline SIC 28 & Chemicals and Allied Products & 8.60 & 14 \\
\hline SIC 29 & Petroleum and Coal Products & 6.27 & 9 \\
\hline SIC 35 & Industrial and Commercial Machinery and Computer Equipment & 8.15 & 16 \\
\hline SIC 36 & Electric Equipment and Components & 10.96 & 14 \\
\hline SIC 37 & Transportation Equipment & 7.93 & 11 \\
\hline SIC 38 & Measurement Analyzing, Control Instruments and Related Products & 13.06 & 8 \\
\hline SIC 48 & Communications & 28.94 & 39 \\
\hline SIC 73 & Business Services & 19.44 & 31 \\
\hline Full sample & & 9.32 & 11 \\
\hline
\end{tabular}

